\title{
LA ACTITUD LITERARIA DE GUILLERMO SAMPERIO: A LA FELICIDAD POR LA INDEPENDENCIA
}

\author{
GUILLERMO SAMPERIO’S ATTITUDE TOWARDS LITERATURE: \\ HAPPINESS BECAUSE OF BEING INDEPENDENT
}

\author{
Rafael PONTES VELASCO \\ Joint Forces Military University (Corea del Sur) \\ rpontesvelasco@gmail.com
}

\begin{abstract}
Resumen: Nuestra intención con este estudio no consiste en subrayar la originalidad de los textos del escritor mexicano Guillermo Samperio, ya analizada en artículos precedentes, sino poner de relieve su actitud abierta y flexible a la hora de leer y escribir. La carencia de prejuicios en la elección de sus afinidades literarias y culturales lo condujo a la felicidad por el camino de la independencia de criterio. En este sentido, realizamos un breve recorrido por las principales corrientes de pensamiento que subyacen en su literatura: las vanguardias, la neovanguardia y la posmodernidad. El comentario de este panorama nos ayudará a entender la predilección samperiana por la microficción, en el marco del hibridismo genérico, y su empleo de la metáfora como destacado recurso estilístico.
\end{abstract}

Palabras clave: Guillermo Samperio; neovanguardia; felicidad; independencia de criterio.

Abstract: The aim of this study is not emphasizing on the originality of the Mexican writer Guillermo Samperio's works, which we have already analyzed in earlier articles, but drawing special attention to its eclectic attitude with respect to reading and writing. Their literary and cultural choices are characterized by the lack of prejudices, in such a way that he achieves happiness with the independence of judgment. In this regard, we briefly research into its literature through the main underlying currents of thought such as the avant-garde, neo-avant-garde or postmodernity. Thereby, we can understand how Samperio selects the microfiction in the framework of the literary subgenres and how he uses the metaphor as a prominent stylistic device.

Keywords: Guillermo Samperio; neo-avant-garde; happiness; independence of judgement. 
La actitud lectora: hacia el idealismo por el sendero de la izquierda

La intención de este estudio no consiste en subrayar la originalidad de los textos del escritor mexicano Guillermo Samperio, ya analizada en artículos precedentes, sino en poner de relieve su actitud abierta y flexible a la hora de leer y escribir. Así, observaremos cómo la carencia de prejuicios en la elección de sus afinidades literarias y culturales lo condujo a la felicidad por el camino de la independencia de criterio.

La obra samperiana se integra en un contexto amplio que podemos concretar en la Ciudad de México, desde mediados de los setenta hasta la actualidad. Su primer libro, Cuando el tacto toma la palabra, se publicó en 1974, mientras que su última entrega fue Volvimos a escuchar ese adagio de Mozart, publicada en 2016, año de su fallecimiento. Un libro de cuentos lleno de lirismo comienza su trayectoria, al tiempo que un libro de poesía repleto de narratividad la cierra. En todo caso, considerando que es una rara avis de las letras hispanoamericanas, la comprensión de sus textos no puede ceñirse en exclusiva a la literatura mexicana de los últimos cuarenta años, máxime cuando estamos ante un autor proclive al hibridismo genérico y al cosmopolitismo.

Su carrera literaria se inició a mediados de los años setenta del siglo pasado, recuperando, sin ingenuidad y con recursos personales, como también hicieron otros neovanguardistas del momento, el espíritu lúdico y las técnicas más valiosas de las vanguardias históricas. Sin embargo, el motivo que impulsó su escritura fue la masacre de estudiantes perpetrada por el gobierno mexicano en octubre de 1968, llevada a cabo con el fin de aplacar las protestas obreras y estudiantiles referidas a una sociedad más justa e igualitaria. La idea inicial de Samperio era denunciar los tristes acontecimientos de su realidad inmediata por medio de la palabra, pero pronto descubrió que su vocación artística lo inclinaba a testimoniar no solo la problemática social, sino también los mundos fantásticos. Dejemos que él nos lo cuente:

Yo quería escribir cuentos contestatarios, sociales y de denuncia, y con ese propósito emprendí mi primer libro de cuentos. Por desgracia o por felicidad, me salieron cuentos fantásticos y absurdos. Junto a Marx, Engels, Lenin o Bakunin, la filosofía de izquierda imperante, también tenía mucho interés por la literatura fantástica y por el obispo Berkeley. Todos los idealistas detestados por Lenin se impusieron en mi escritura por ellos mismos, sin que nadie me hubiese aleccionado: Borges, Cortázar, Jarry, Girondo, Gómez de la Serna, Gombrowicz, Ionesco, Arrabal... (Samperio en Pontes Velasco, 2003: 56).

Afiliado a organizaciones de izquierdas, desde muy joven se interesó por los manuales de referencia de las ideologías marxistas y anarquistas. En su investigación de los tratados de Lenin, halló varias citas de párrafos completos del obispo Berkeley. Paradójicamente, el afán leniniano por desprestigiar y rechazar el idealismo desembocó en la fascinación de un nuevo seguidor de la causa berkeleyana. En las entrevistas que le realicé para completar mi tesis doctoral insiste, con conceptos semejantes, en el mismo proceso: 
Junto a Marx, Engels, Lenin o Bakunin, la filosofía de izquierda imperante, leí al obispo Berkeley, Diderot, D’Alambert, Ortega y Gasset, Sartre y Camus, además de literatura absurda, experimental y fantástica. Durante el movimiento estudiantil de 1968, preso y torturado, tuve la mala fortuna de presenciar varias muertes. La lectura de Camus me provocó la escritura en ese momento y me llevó a testimoniar lo que estaba sucediendo en mi entorno; pero no en el sentido de connotación historiográfica o periodística. Leer a Lenin a veces me aburría. Me sentía culpable de pensar que Berkeley es un gran señor y Borges uno de sus hijos latinoamericanos más esplendorosos. Quise denunciar las injusticias que presencié, pero tuve el arte en cuenta desde el principio (Samperio en Pontes Velasco, 2013: 589).

Como consecuencia de esta suerte de `autodidactismo anárquico' que guíaba sus lecturas, Samperio se dio cuenta de que la literatura que le interesaba escribir no podía reducirse a elegir un bando en la pugna entre materialistas e idealistas. El materialismo establecía una distinción dual entre "cosas" e "ideas", mientras que el idealismo, a pesar de su sesgo burgués, antirrevolucionario y reaccionario, abogaba por postulados afines a las inquietudes samperianas, tales como el cuestionamiento a las teorías newtonianas del espacio absoluto o de la gravitación. No olvidemos que Samperio, a medida que se desliga de todo sistema que pueda condicionar u orientar el contenido de sus textos, con los años adquiere una religiosidad idiosincrásica de la que hablaremos más adelante. Mientras tanto, acompañemos sus reflexiones:

Como era ultrarradical de izquierda, marxista, leninista, maoísta, malthuseiano, schumpeteriano... obviamente, cuando empecé a escribir quería denunciar las barbaridades de la burguesía y de sus súbditos: el ejército, las policías secretas y todo eso. En realidad, cada vez que escribía un cuento de corte social y de denuncia, me salía uno fantástico. Recuerdo que leí un libro muy grande y tortuoso de Lenin que se llamaba Materialismo y empiriocriticismo, nada más el nombre era como de adivinanza. Como era tan mal polemista por escrito, Lenin hacía citas enormes de idealistas como el obispo Berkeley, Lambert, etc. Y me olvidaba de las citas de Marx y Engels, que eran más chiquitas. Me maravillaba con los idealistas, me parecía fantástico lo que decían. Por culpa de Lenin me hice idealista. [...] Por eso admiro al Che Guevara, creo que era más berkelyano que marxista (Samperio en Pontes Velasco, 2013: 639-640).

En esta alabanza implícita al esse est percipi y a las sensaciones humanas como principales responsables de las cualidades que atribuimos a las cosas, Samperio alude posiblemente no solo a obras de Lenin como Materialismo y empiriocriticismo (1909), sino también a las cartas que el político ruso escribió a Máximo Gorki, fechadas entre febrero y abril de 1908 y noviembre y diciembre de 1913. En dichos textos la finalidad de Lenin no era únicamente criticar los berkeleyanos Tratado sobre los principios del conocimiento humano (1710) y Los tres diálogos entre Hylas y Philonus (1713), ya que su objetivo residía en refutar a los que él consideraba falsos marxistas, los "machistas" o adeptos a las doctrinas del filósofo austríaco Ernst March.

Quizá lo más interesante de las objeciones que Samperio encuentra en su interpretación de los textos de Lenin radica en la necesidad de apostar por la forma artística por encima de las denuncias sociales. Su predilección por la literatura en sí misma lo enlaza con otro idealista: Jorge Luis Borges. La sospecha borgesiana de la existencia de la realidad afecta a la noción de una continuidad científica basada en la sistematización. La filosofía que duda tanto de la consistencia del sujeto perceptivo como de lo percibido aboca a la desaparición de los postulados tradicionales acerca del espacio y el tiempo: "Fuera de cada percepción (actual o conjetural) no existe la materia; fuera de cada estado mental no existe el espíritu; tampoco el tiempo existirá fuera de cada instante presente" (Borges 1989: 146). 
El mismo Borges, en su ensayo "Nueva refutación del tiempo", perteneciente a Otras inquisiciones, declara su preferencia por la doctrina berkeleyana sobre la del naturalista y escéptico David Hume. Mientras que la originalidad de éste estriba en la supresión del sujeto, la del idealista irlandés va más allá al cuestionar los objetos:

\footnotetext{
El idealismo es tan antiguo como la inquietud metafísica: su apologista más agudo, George Berkeley, floreció en el siglo XVIII [...] y negó la materia. Ello no significa, entiéndase bien, que negó los colores, los olores, los sabores, los sonidos y los contactos; lo que negó fue que, además de esas percepciones, que componen el mundo externo, hubiera dolores que nadie siente, colores que nadie ve, formas que nadie toca (Borges, 1989: 144).
}

Posiblemente este tipo de preocupaciones existencialistas era lo que apasionaba a Samperio cuando reivindicaba a Berkeley. De hecho, a partir de la publicación de Textos extraños (1981), afianza su interés por renovar los temas fantásticos a través del sondeo del entorno inmediato, a contracorriente de lo que postulaban otros escritores progresistas de la época. Por otra parte, la actitud de 'dejar volar' su imaginación, sin obsesionarse con cuestiones ajenas a la literatura, lo libera de la angustia que le producía la excesiva autoconciencia crítica. Al abandonar la escritura sustentada en los avatares políticos, opta por una elaboración más 'clásica' de la expresión literaria y por una alianza indisoluble con la estética a fin de encarar cualquier género literario con libertad y pulso experimentador. Un mayor espíritu lúdico fluye entonces en unas composiciones caracterizadas por lo imaginativo en cuanto al fondo y por la hibridación genérica respecto a la forma.

Si bien otras lecturas determinantes en la formación literaria de Samperio fueron en gran medida las esperables en el ambiente progresista de los años sesenta y setenta, las singularidades de su formación como escritor resultan muy destacables. Retomando el asunto de la religiosidad, especialmente relevante en el México de esos años, sigamos las huellas de los libros que leyó y se imprimieron en su talante:

Fui católico hasta la edad de veinte años; fervoroso, paranoico. Concebía al Ángel de la Guarda y a Dios como persecutores. Hasta que leí Ludwig Feuerbach y el fin de la filosofía clásica alemana, de Federico Engels: no entendí la mitad, pero supe muy bien que Dios no existía. Se redujeron la paranoia y la culpa, y descansé. Después de ocho años de psicoanálisis, cerca ya de los treinta y ocho, empecé a sentir la necesidad de reconocer la parte de religiosidad que había en mí. Busqué en múltiples religiones y llegué a la conclusión de que no podía pertenecer a ninguna iglesia. Decidí ser librepensador, mi propio sacerdote, mi propio fiel; controlando más al punitivo que al nutritivo. Cuando volví a ser creyente, me di cuenta de que no podía pertenecer a ninguna religión concreta. Soy consciente de que las religiones se someten a restricciones y puntos vacíos. El mundo es tan diverso y múltiple que tomar partido me parece absurdo. ¿Por qué no tener dos dioses, dos culturas? (Pontes Velasco, 2013: 598).

La religiosidad de Samperio, sustentada en la independencia de criterio y en la reflexión individual, asumida y contrastada tras acudir a diversas fuentes, cristaliza en un sincretismo único, nacido del cruce entre diversas religiones: desde la árabe hasta la precolombina, desde la cristiana hasta la interiorizada consecuentemente. Observemos hasta qué punto la heterogeneidad prevalece en su pensamiento:

Si bien lo árabe y lo español me llevaban a la creencia en un solo dios, en mis investigaciones de historia precolombina descubrí que la imagen de Tláloc estaba recogida en un texto muy temprano del siglo 
XVI. No era sólo un dios de la lluvia, sino dios de dioses. Se encuentra la misma efigie en distintas regiones, incluso donde llovía mucho. Como no encontraba expresada mi parte indígena, asumí una dualidad que en realidad es una trinidad, ya que Alá está incorporado a Dios Padre. En mi binomio, el dios occidental tiene un quince por ciento de Alá. Tláloc, por su parte, resulta de una combinación de lo masculino y lo femenino: dos serpientes que flotaban sobre el espacio infinito sin encontrarse, hasta que en un instante galáctico se dan aliento. Equivale a dos serpientes enfrentadas, enredadas en un cuerpo triturado. Nuestra columna vertebral tiene un sistema celular semejante al de las serpientes. La Santa Inquisición reprimió el erotismo y el lenguaje. Por eso los mexicanos tenemos este apego por los dioses precolombinos. Hubo un gran debate en mi congregación interna; una discusión de mis “yoes”, ya que tengo más de occidental que de indígena. Debo mostrar mi sangre indígena no expresada, al menos a través de la religión. Poseo formación occidental, pero también un vínculo fuerte con mi madre (Pontes Velasco, 2013: 597-598).

El eclecticismo basado en la plena autonomía signa las tomas de postura samperianas, incluso las ideológicas. Así, la filiación política de la que hacía gala en sus primeros libros pasa de una reflexión de tendencia izquierdista a un compromiso global con la humanidad, caracterizada por la observación sin prejuicios a la hora de denunciar cualquier tipo de injusticia. Cuando repasa su trayectoria se refiere en estos términos a sus primeras publicaciones, previas a Textos extraños:

Luego escribí cuentos sociales, siempre con la forma literaria como dominante; trabajando hacia el interior de los personajes más que a su decir, y con eso evité el panfleto tan recurrido en los sesenta. Eran textos que mostraban las contradicciones de la gente de izquierda, dirigiéndome hacia nuevas formas de moralidad (Pontes Velasco, 2013: 589).

En 2002, ya consagrado como autor de literatura fantástica, reconoce que, pese a su solidaridad con los desfavorecidos y su afán por señalar y poner el dedo en la llaga sobre las injusticias sociales de cualquier procedencia, su estancia en el mundo se corresponde con la de un artista abierto a cualquier aprendizaje, dejando en una posición más secundaria su labor como activista político:

Lo mismo he hablado en Radio Martí que publicado en Casa de las Américas; sé que ambos medios se sitúan en un extremo. Lo importante son las personas. Cuando participé como observador electoral en el territorio zapatista, estuve cercano a la curia de San Cristóbal. No me gusta escuchar misas; prefiero entrar en una iglesia cuando ésta se encuentra en silencio y ofreciendo su frescura. Conocer a gente diversa me parece importante para un artista, porque permite percibir otras miradas del mundo (Pontes Velasco, 2013: 598).

Para finalizar con este apartado relativo a las lecturas de Samperio cabe decir que, hasta el final de su vida, continuó tanto con su formación lectora como con su original eclecticismo. Así, a la pregunta de qué lecturas le atrapaban en 2006, demuestra su curiosidad insaciable por el conocimiento en este párrafo:

Voy muy avanzado en mis clases de clásicos y estoy empezando a tomar clases de latín. Me ha encantado un texto de título "Escudo", atribuido a Hesiodo, sobre el escudo de Heracles. Me emociona introducirme en los textos arcaicos. Paralelamente he empezado Julio César, de Shakespeare, tras haber terminado el maravilloso Antonio y Cleopatra. Es en verdad un genio y para mí sería el único autor, aparte de los grecorromanos, al que incluiría entre los "clásico - clásicos". A partir de ahí, los otros clásicos se constituyen por país, como nuestra Sor Juana Inés de la Cruz y nuestro Carlos de Sigüenza y Góngora. En medio del desastre, por lo menos he seguido leyendo y estudiando letras clásicas, como a los presocráticos y a Platón (Samperio en Pontes Velasco, 2013: 643). 


\section{La actitud escrita: del eclecticismo al hibridismo}

En este capítulo vamos a analizar las escrituras de Samperio a través de una concepción amplia, alusiva más a sus grandes líneas que a sus textos concretos. Para ello, realizaremos un breve recorrido por las principales corrientes de pensamiento que subyacen en su literatura: las vanguardias, la neovanguardia y la posmodernidad. El comentario de este panorama nos ayudará a entender la predilección samperiana por la microficción, en el marco del hibridismo genérico, y su empleo de la metáfora como destacado recurso estilístico. Decidido a consagrarse como escritor total, el cultivo de diversos géneros literarios lo convierte en excepcional, incluso en sus manifiestos.

La etimología del término avantgarde, que alude al tecnicismo militar de avance, se corrompe cuando, tal y como Enzensberger indica en "Las aporías de la vanguardia", llega el "surgimiento de una vanguardia como bluff, como fuga hacia adelante, en la que participa el grueso por temor de quedar rezagado" (1963: 9). Frente a la incertidumbre por saber qué composiciones están por delante de otras, el poeta alemán recuerda que creadores como Marcel Proust, William Faulkner, Bertolt Brecht, Samuel Beckett, Heinrich von Kleist o Franz Kafka desconocían el calificativo "vanguardista" con que suele denominárseles, probablemente porque sólo la posteridad puede otorgar un lugar capaz de sustraerse a los pronósticos. En su opinión, las obras maestras se consolidan en el equilibrio "de una índole donde lo decisivo son los saltos. Con la espontaneidad con que éstos se producen no puede ninguna teoría del futuro" (10-11).

En Hispanoamérica, el pluralismo de motivos y formas se afianza con el brío contracultural de los años sesenta y setenta, donde se recobra el espíritu transgresor e iconoclasta de principios del siglo XX. Aunque los neovanguardistas tampoco pueden ofrecer soluciones a la alienación del sujeto que tanto angustiaba a sus predecesores, en términos generales su modus operandi trata de evitar la pose elitista del modernismo o de las vanguardias históricas para alcanzar la respuesta de un número más amplio de personas. Con ironía y sin la vocación trascendentalista de sus mayores, los autores del Boom perfeccionan muchos de los planteamientos utópicos anteriores con el acento en una narrativa interesada más por la edificación que por lo deconstructivo. Julio Cortázar, con obras como Rayuela (1963), da un crucial paso adelante en esta dirección por medio de propuestas de metarrelatos representativos de su momento histórico en los que, no obstante, predominan las técnicas vanguardistas.

Entre otros narradores que influyen a Samperio en esos años podemos destacar, por sus aportaciones textuales de compleja delimitación genérica, además de a Cortázar, con libros incasillables y experimentales como Último round (1969), Fantomas contra los vampiros multinacionales (audaz cómic de 1975), o Territorios (1979); a Guillermo Cabrera Infante, con sus arriesgados Tres tristes tigres (1964 y 1967), O (1975), o Exorcismos de esti(l)o, (1976); y a Augusto Monterroso quien, con una hibridación desbordante de ensayo y cuento convierte, gracias a la sátira, el dogmatismo proverbial de las fábulas tradicionales en ruptura imprevisible de tópicos, tal y como se aprecia en La oveja negra y demás fábulas (1969). 
Junto a los citados, Samperio se identifica con escritores outsiders de difícil pista, de ahí que sea complicado rastrear las referencias intertextuales de varios de sus escritos. El eclecticismo de sus intereses se explica por su carácter abierto, que lo lleva a 'viajar' por libros de diversos países, épocas y géneros. Sus primeros años como escritor coincidieron con la mencionada eclosión del Boom, si bien en su obra se refleja tanto la influencia culta de los ateneístas mexicanos (sobre todo de Julio Torri y Alfonso Reyes) como la impronta popular del grupo literario conocido como La Onda (con José Agustín a la cabeza). De esta combinación de elementos casi opuestos, del estilo clásico de los primeros al jergal de los segundos, deriva la peculiaridad de las creaciones samperianas. Sus composiciones oscilan entre el realismo más crudo y el lirismo más delicado gracias a sus hallazgos personales, pero no es menos cierto que esta heterogeneidad estilística nace del legado que dejan en él ensayistas, narradores y poetas de todo el planeta.

Samperio ofrece con voz propia un cosmos inédito o apenas sugerido por otros autores. La diversidad de su obra, proclive a ese 'salto' de una forma de escribir a otra, esa acrobacia que Enzensberger estima distintiva de la actitud vanguardista - de lo realista a lo fantástico y viceversa -, se comprende por la cantidad de maestros que tuvo y a los que rindió homenaje con sus textos. En su opinión, "la evolución de la literatura no sería posible sin la imitación, ahí está precisamente el avance. Primero se imita, después se propone. No hay otro camino" (2008: 30).

Gérard Genette, en Palimpsestos: la literatura de segundo grado, aclara la terminología de las nuevas maneras de imitación distinguiendo la intertextualidad tanto de la hipertextualidad como de la metatextualidad. La primera se ciñe, en la división del crítico francés, a las citas y referencias textuales puntuales; de ahí que se relacione con la elocutio -sobre todo de la lírica - y su campo de estudio lo abarque preferentemente la estilística. Con la segunda, se señala el potente influjo de las macroestructuras de las obras, como el que ejerce la dispositio de la Odisea en la organización de la Eneida o del Ulysses, de Joyce. La tercera se resume en la conexión del texto con su comentario (Genette 1982: passim).

La intertextualidad engendra palabras iguales en territorios disímiles, zonas textuales que se repiten estratégicamente para dotar de calidad artística a la nueva página resultante. Como la antigua fórmula escolástica dixit, este mecanismo recurre a la potestad de lo escrito para seducir al lector. Sin embargo, el principio de autoridad se tiñe de ironía cuando se anulan los límites entre la creación y su exégesis. En este punto llega la posmodernidad, polémico movimiento cultural que, sin rechazar la herencia literaria, favorece críticas lúcidas de los modelos canónicos y hegemónicos precedentes. Esta epistemología favorece que se alcen puentes instintivos entre escritores distantes en el tiempo y/o en el espacio, aportando luz a semejanzas ocultas. La literatura, como el mundo, se transforma en un 'pañuelo' donde los paralelismos y coincidencias circulan a sus anchas.

Jaime Alazraki, en "La postmodernidad de Julio Cortázar", reconoce la huella de una evolución literaria "que se origina en América e influencia la literatura europea, con Borges como escritor que ha contribuido más que ningún otro a la invención y aceptación del nuevo código" (1995: 129). En efecto, los textos borgianos se adelantan a su siglo en muchos aspectos. Alentado por las teorías de 
Berkeley, el autor argentino concibe el escepticismo como un eficaz método oblicuo de enfrentarse a las paradojas. Simultáneamente, anuncia la estética de la recepción cuando contrapone el orden finito de la escritura al infinito de la lectura. En cierto modo, su imaginación engendra el 'monstruo' de la posmodernidad. En esta dirección, la gran corriente posmoderna que asume Samperio es la borgiana, fundada en la noción de que ninguna conclusión es irrefutable y de que cualquier tesis incluye la hipótesis opuesta.

Borges crea una poética basada en el alejamiento de la falacia biográfica y en la idea de que la mayoría de los países aparecen encarnados fatalmente por un paradigma literario que, en realidad, no los representa en absoluto. A su modo de ver, este anatema evidencia la impronta del renacimiento italiano en Cervantes y Shakespeare, así como los rasgos anglosajones de su propia narrativa. Lo relevante del enigma borgiano reside en su negativa a dividir la historia de la literatura en función de fronteras geográficas y en su rechazo a clasificarla según identidades nacionales.

Esta afirmación de que tan sólo hay literatura, lo que en sí no es poco, conduce al poeta Juan Antonio González Iglesias a aseverar que "la única genética posible es la cultural, especialmente literaria. Por eso, no siendo los españoles unos latinos de sangre, sí cuentan entre los suyos a Séneca y a Lucano" (2003: 605). El narrador Jorge Volpi se sitúa en la misma línea al precisar que los ateneístas -que con tanta devoción siguió Samperio- se caracterizan por su actitud abierta a todos los conocimientos:

Fueron acusados de copiar modelos extranjeros y de dejarse seducir por las tendencias de moda, cuando en realidad hacían lo contrario: fundar y preservar la mejor tradición literaria del país, esa tradición que, a fuerza de ser generosamente universal, como señaló Reyes, también era provechosamente nacional (Volpi, 2008: 151).

Dando un paso más allá, el mismo Volpi asegura que Roberto Bolaño propaga tal epidemia que después su muerte no podemos hablar ya de literatura latinoamericana, pues esta se ha internacionalizado: "Murieron con él, a veces sin darse cuenta - aún hay varios zombis que deambulan de aquí para allá -, todos los escritores latinoamericanos. Lo digo clara y contundentemente: todos, sin excepción" (2008: 236). Tras él no existiría en sentido estricto ningún escritor latinoamericano sino, en todo caso, algún “mexicano, chileno, paraguayo, guatemalteco o boliviano" (236).

En esta línea, no extraña que Ricardo Piglia afirme que "la verdadera tradición es clandestina y se construye retrospectivamente y tiene la forma de un complot" (2000: 80). Francisco Umbral cree que los únicos puntos comunes que poseen los artistas son la desubicación y "su modo peculiar de huir, y en eso sí que los creadores imaginativos son fieles a su momento" (1977: 207-208). Juan José Millás añade que cualquier movimiento literario es susceptible de recibir múltiples interpretaciones y que supone "un disparate estudiar juntos a Campoamor y a Kafka, incluso a Borges y a Canetti, aunque todos escriban. Y al lado de esas mil historias manifiestas, hay también una historia de la literatura invisible, por la que vagan los autores que no permanecieron" (Millás 2001: 39).

Samperio corrobora estas ideas en sus escritos, donde se aprecia la dirección doble y simultánea que delinea su trayectoria: por un lado, la influencia de los clásicos; por otro, la de los marginales. Al 
igual que le sucede a Medellín, joven científico de su novela Anteojos para la abstracción, compensa la ausencia de estudios universitarios con su inmersión en una investigación autónoma e independiente, caracterizada por "la indagación individual, el ensimismamiento, hundirse en un libro y que de éste se fueran desprendiendo los otros, en una bibliografía azarosa y ecléctica" (1994: 42). La variedad de sus inquietudes se refleja en la riqueza de los materiales con que se nutre, consciente de los vínculos que la literatura establece con disciplinas como la filosofía, la política o incluso la psicología analítica.

Samperio, en su ensayo “¿Escritor o bailarina?”, hila más fino al estimar que la mejor manera de respetar al maestro consiste en que no se note su ascendencia:

\footnotetext{
No es recomendable escribir como Baudelaire ni como Swift, pero sí podemos apropiarnos de su actitud; ellos indagaron sensiblemente en su época, en los rostros ocultos de sus sociedades y de las costumbres de sus pueblos; y en su escritura aplicaron también conocimientos de lenguaje, pero fueron más allá de éstos, los hicieron explotar, se negaron a la coherencia de las anteriores escrituras (Samperio, 1987: 52).
}

Es cierto que la literatura mexicana, como las demás artes nacionales, acepta ordenaciones, diversificaciones y corrientes convergentes o divergentes que se suceden a lo largo de las décadas a través de generaciones de creadores diferentes entre sí. Empero, la órbita de los cultivadores de la literatura neofantástica o de imaginación que influyen en el México donde nace Samperio propicia el diseño de un árbol genealógico internacional, prácticamente ilimitado y difícil de precisar con exactitud. Así como los años sesenta del siglo pasado se afianzan como paradigmáticos de la desintegración de los moldes genéricos conocidos hasta el momento, entre finales de los setenta y principios de los ochenta se consolida lo que nuestro autor denomina, en su artículo "La fícción breve", la "literatura fragmentaria" (2004a: 67). Durante esas décadas, y más aún con posterioridad, se revalorizan los pensamientos de los filósofos presocráticos, distinguidos por la ausencia de unidad orgánica en su temática, a la vez que se publican numerosas colecciones de aforismos y epigramas.

El concepto de género literario puede explicarse desde el punto de vista del emisor del mensaje, situando a cada texto en una serie histórica y 'de linaje' con la que se asemeja parcial o totalmente. A partir de su herencia genética, los géneros engendran la obra correspondiente, al tiempo que aportan un primer marco de referencia para el lector. Los escritores, de este modo, parten de una actitud implícita de apoyo o rechazo hacia el canon que tratan de superar. Según la postura literaria que se asuma, obtenemos una cantidad y una determinación genéricas distintas. Desde la perspectiva del receptor, el público de todas las épocas posee conciencia, intuitiva o fundada, de los paradigmas genéricos.

En el caso de Samperio, la quiebra de los géneros literarios tradicionales puede entenderse dentro de una teoría abierta que desestabiliza las consideraciones al uso y elimina las barreras drásticas entre las diversas expresiones artísticas. Tal vez no se puedan escribir volúmenes imprescindibles en nuestros días, sino pequeñas reseñas de 'marginales quijotes', pero la ruptura de fronteras entre géneros facilita que se amplíen los límites del canon tradicional. La superación de las restricciones genéricas constituye para nuestro autor un aspecto clave de un periodo de crisis literaria que afectó a todas las dimensiones de su escritura. Por eso, en "Prólogo. Damas fantásticas", resume con precisión que los 
"géneros literarios existen en niveles diferentes de generalidad y esta noción se define por el punto de vista elegido" (2002b: 7).

No en vano el subgénero o género conocido como microficción se abre paso en la posmodernidad, quizá el tiempo histórico en que se conceden mayores oportunidades a los escenarios otrora olvidados y a los creadores menos conocidos. Aunque todo esté escrito, aún pueden revelarse secretos a través de lo microscópico. La disyunción de los fenómenos culturales aquí descritos (la literatura sin límites nacionales, la hibridación genérica, etc.) desemboca en la obra de Samperio, donde la brevedad se transforma en un signo básico de su identidad literaria.

Frente a la división convencional entre narradores y poetas nuestro autor, desde el principio de su carrera, aborda diversos géneros tanto a la hora de hilvanar tramas como a la de realizar experimentos con el lenguaje. La brevedad adquiere para él una posición relevante en las letras hispanas de los últimos siglos, alcanzando la excelencia con sus principales cultivadores. En México, estima al mencionado Julio Torri y a Juan José Arreola como los "padre y padrastro de la ficción breve" (2004b: 129) y, por lo que respecta a España, concede dicho honor a Ramón Gómez de la Serna y Rafael Pérez Estrada.

Digno sucesor de ambas tradiciones, la mexicana y la española, Samperio se alza como el hijo o ahijado ideal, sirviéndose de variadas técnicas para escribir textos que fluctúan entre los géneros canónicos y los inventados. En el caso de los españoles indica dos grandes tendencias, situándose entre la espontaneidad del primero, quien inaugura con sutileza "la psicología portátil de lo real [...] una fantasía virginal, como la de un niño ante las cosas pequeñas, que describe las habitaciones y personaliza los utensilios, los objetos más olvidados" (2004b: 131), y el exquisito barroquismo del segundo, quien suscita "un arrebato de la intuición, una llameante fugacidad de la ocurrencia, afianzada por la poesía" (132).

Samperio, a fin de profundizar en los ‘trucos` literarios con los que estructura sus composiciones, publicó "Brevedades literarias" y "Brevedades de la prosa” en su sección Tekstos de la Kómoda, en el Cultural del periódico El Financiero. En estos artículos desarrolla su visión de la greguería, a la que califica de "opuesto más radical a la novela histórica" (2002a: 52). En su opinión, los antecedentes del subgénero pueden rastrearse en el pasado remoto:

Proviene desde los epigramas mortuorios de la antigüedad (los escarabajos con inscripciones de bienaventuranza que los egipcios les colocaban a sus muertos, o la de los griegos al pie del edificio mortuorio) hasta los aforismos modernos de Séneca, pasando por la sentencia, la máxima y los eslóganes (Samperio, 2002a: 52).

Los microtextos, pequeños pero 'matones' herederos de las greguerías, se erigen dispuestos a transformar la historia con cada irrupción, más conscientes que nunca de lo azaroso y hermoso de los cánones. En este sentido el escritor Luis Landero, resguardado bajo el sobrenombre del Círculo Cultural Faroni, rinde homenaje, de forma emotiva, hermosa y teñida de subjetividad, a la tradición literaria con su "Breve antología de la literatura universal": 


\begin{abstract}
Canta, oh diosa, no sólo la cólera de Aquiles sino cómo al principio creó Dios los cielos y la tierra y cómo luego, durante más de mil noches, alguien contó la historia abreviada del hombre, y así supimos que a mitad del andar de la vida, uno despertó una mañana convertido en un enorme insecto, otro probó una magdalena y recuperó de golpe el paraíso de la infancia, otro dudó ante la calavera, otro se proclamó melibeo, otro lloró las prendas mal halladas, otro quedó ciego tras las nupcias, otro soñó despierto y otro nació y murió en un lugar de cuyo nombre no me acuerdo. Y canta, oh diosa, con tu canto general, a la ballena blanca, a la noche oscura, al arpa en el rincón, a los cráneos privilegiados, al olmo seco, a la dulce Rita de los Andes, a las ilusiones perdidas, y al verde viento y a las sirenas y a mí mismo (Círculo Cultural Faroni, 1996: 51).
\end{abstract}

Entre los recursos retóricos de orden semántico, Samperio dedica una atención privilegiada a la metáfora, favoreciendo con ella una comprensión más completa de lo que nos rodea. Su configuración se origina a partir de una tesis aristotélica, la que dice que la habilidad para producir tropos originales debe considerarse como la categoría superior de la poesía: "Lo más importante es ser apto para la metáfora, ya que esto es lo único que no puede tomarse de otro y es señal de talento. Pues metaforizar bien es intuir las semejanzas" (Aristóteles cit. López Eire 2005: 23).

Nuestro autor asume que, si bien su condición de narrador contemporáneo ha de estar presidida por la ironía, su don de poeta depende fundamentalmente de su buen uso de la metáfora. De ahí que herede las premisas del Conde de Lautréamont, para quien esta figura retórica "presta muchos más servicios a las aspiraciones humanas hacia el infinito de lo que se esfuerzan en imaginar, de ordinario, quienes están imbuidos de prejuicios o ideas falsas, lo que viene a ser lo mismo" (1868: 172). De esta sentencia proviene el siguiente paso en el desarrollo estilístico de Samperio, consistente en dominar las imágenes surrealistas que, como explica Víctor García de la Concha en El surrealismo, cuentan con sus peculiares requisitos:

En la imagen de tipo tradicional la base para la asociación de dos realidades es su analogía de tipo mórfico o axiológico, en la imagen surrealista la base es radicalmente convencional y extremadamente subjetiva, apoyada, con frecuencia, en la asociación de significantes sin tener en cuenta los significados que les corresponden (García de la Concha, 1982: 25).

Samperio se mantiene abierto a la finalidad persuasiva de los retóricos antiguos en el empleo de los procedimientos irónicos, como corresponde a su coherente asunción de la posmodernidad de corte borgiano, pero los plasma en una concreción artística donde la metáfora - "la forma breve (brevitas) de la comparación" (Lausberg 1967: 61) - se convierte en su seña de identidad. Esto exige un receptor incisivo y dispuesto a descifrar los conceptos o, al menos, a comprender su dificultad como un elemento fundamental del universo que plantean los textos. La virtus brevitatis se impone así como la clave de una poética perfectamente articulada para generar belleza a partir de la consciencia de las estrategias retóricas a disposición.

Esta destreza se nota particularmente en uno de sus muchos relatos de corte lírico, llamado “Después del mar está el mar". En este cuento, uno de sus más logrados y significativos, la narración parte de los pensamientos poéticos de un viajero que traza una ruta incierta en busca de su amada: "En verdad, no sabía si ese amor alguna vez se albergaría en el ave que tengo en lugar de corazón, en tanto que fui preparado para la guerra, e imagino en este momento al halcón que desfallece en mi entraña" 
(Samperio 2006: 493). A continuación leamos cómo se forja la intensidad de una escritura única, generada a partir de la metáfora:

Entendí que había un significado detrás del mío, pero aún oculto en el fluir de las aguas subterráneas de mi templo. La voz vino esta vez desde el hoyanco que había podido cavar en no sé cuánto tiempo. Mi impulso fue seguir extrayendo arena hasta que me topé con una placa de cristal. [...] Bajo la traslúcida lámina distinguí una cara de piel blanquísima, su cabellera pelirroja; me miraba con unos ojos verde marítimo y su divisar me decía "Sálvame, estoy aquí por los siglos de los siglos, esperando; observa bien mis ojos". [...] La primera duna elevada que vi desde que murieron mis camellos y recompongo la frase de la mujer: "Después del mar sepia está el mar Mediterráneo". Cierro los ojos, miro hacia mi interior y descubro que el árbol de luz ha crecido; tiene pequeños frutos, o botones de flores a punto de explotar, todavía más luminosos que el tronco y sus ramas. No puedo evitar el llanto sereno, líquido proveniente, con seguridad, de mis ríos subterráneos. Aún con los ojos cerrados, siento que La Doncella del Nilo me abraza y yo a ella. Se hacen más claros para mis oídos los tumbos de las olas que esparcen espuma sobre una playa virgen. Abro la mirada y están frente a mí los ojos glaucos sonriendo. Tomados del brazo empezamos a salvar la duna alta con pies, por primera vez, firmes (Samperio, 2006: 494-495).

Volviendo a la cuestión de las influencias y conectándola con la utilización de la metáfora como recurso expresivo e idiosincrásico, recalquemos que Samperio recibe el influjo directo tanto de Gómez de la Serna, quien funde con maestría anécdota y lirismo - "Al ponernos al oído aquella caracola escuchábamos ruido de mar y gritos de náufragos" (Gómez de la Serna cit. Brasca y Chitarroni 2004: 101) - como de Pérez Estrada. El malagueño destaca tanto por el sensualismo como por la fantasía desbordada de sus símiles, suscitados por bellas argumentaciones. Así ocurre en "Sobre la lógica y sus vicios":

El silogismo militariza y nos conduce a los terrenos tediosos de la lógica. Por el contrario, el sofisma es antropofágico y se abre a la locura creativa y al esplendor de lo incierto y lo mágico. El silogismo entristece como la receta de cocina de un plato demasiadas veces repetido. El sofisma es virginal, cristalográfico y tiene brillo propio (Pérez Estrada, 2001: 233).

El análisis de las escrituras samperianas corrobora que sus "ficciones breves", respetando la terminología que prefiere, cohabitan con todo tipo de creaciones dentro de volúmenes tan heterogéneos como Cuentos reunidos (2006) o Maravillas malabares (2015). La polisemia de esta nomenclatura se afina más si acudimos al sintagma que acuña para describir la apuesta literaria de Pérez Estrada en su Antología de breve ficción (Samperio 2010: passim). El vocablo "breve ficción", aplicable a la labor del mexicano tanto o más que a la del poeta español, se inserta en la tradición literaria otorgando una posición preferente a temáticas innovadoras y reforzando la apertura estilística de las brevedades. En ellas esencialmente radica la consagración de nuestro 'Gulliver' Samperio como escritor perdurable.

González Iglesias, en "El triunfo del architexto", explica que en la obra de Pérez Estrada "sólo renunciando a la extensión larga se puede lograr que sean simultáneos el poema y la narración [...]; lo poético [...] es algo sustantivo [...], una magia difícilmente expresable por la racionalidad" (1999: 221). Recordemos que Samperio, al atribuir el sintagma "breve ficción" a las brevedades perezestradianas, e indirectamente a las suyas, convierte el adjetivo en nombre. Si tomamos lo poético y lo breve como esencias, con más facilidad comprendemos que la asunción del verso y de la prosa, por parte de los amantes de las brevedades, se aborda con criterios tan amplios como relativos. Sí, la microficción alude a la escritura que explora los imprecisos límites de lo micro y lo ficcional, pero para su 
afirmación necesita lo macro y la no ficción. Así lo demuestra nuestro autor cuando en varios de sus libros alterna relatos largos con poemas y minitextos.

Respetando los conocidos términos de Genette, sin separarlos drásticamente, podemos aducir que Samperio mantiene un sólido compromiso con la "ficción" de lo imaginario tan sólo equiparable al que guarda con la "dicción" de la realidad. Por este motivo, en su lúcido artículo "La palabra como personaje sin camión: Annie Saumont", confiesa con valentía las intenciones últimas de su empresa literaria: "La literatura es búsqueda, es forma, es la vida misma que cambia, evoluciona" (2000: 116).

En su ensayo "Novela y posmodernidad", perteneciente a Tribulaciones para el siglo XXI, delimita su posición al respecto de la cuestión candente y admite la oscuridad en que se halla el concepto mismo de epistemología. Señala que, a principios de los ochenta, las transformaciones acontecidas en la sociedad demandaban nuevas formas de representación artística. Paralelamente al aminoramiento de las distancias geográficas por el alto desarrollo de los medios de transporte, se genera una "crisis expresiva" de difícil resolución:

Esta hecatombe creativa anunció, de manera implícita, otras crisis, como la caída de los sistemas de pensamiento y los sociales, tal la de la semiótica y del muro de Berlín, respectivamente. La llamo crisis de expresividad porque en esta ocasión lo que apareció en el horizonte de los creadores fue el vacío, la nada y, junto con ellas, la angustia de imposibilidad creativa, atrapados en sus entonces ya pobres y desfallecientes herramientas, heredadas de Joyce y Faulkner, Mallarmé y Vallejo, Beckett e Ionesco, Duchamp y Warhol, Buñuel y Bergman, Martha Graham, entre muchos más. Los caminos que abrieron ellos arribaron al abismo (Samperio, 1999: 258).

Ahora entendemos mejor cómo a partir de su cuarta entrega, Textos extraños, Samperio se aleja del silencio al que abogaban las vanguardias históricas, conserva los recursos más valiosos y abraza la felicidad en sus escrituras. Como acertadamente anota Cecilia Durán en un estudio, "sus primeros libros los creaba con angustia, pero con psicoanálisis venció la resistencia y, a partir del cuarto libro,

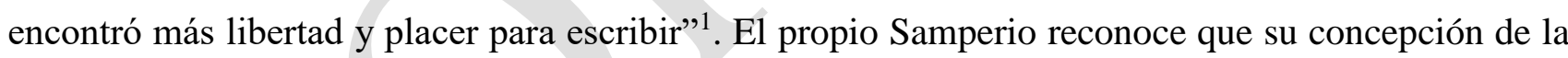
literatura se debe a "un sondeo en la existencia, es un proceso de indagación. [...] En mi primera época, la escritura era muy angustiante para mí [...]. Hoy en día, cuando escribo es un placer, un juego" (Samperio, 2007) $)^{2}$.

\section{La actitud creativa: a la felicidad por la independencia}

La felicidad como objetivo de las escrituras de Samperio debe entenderse en términos de un cumplimiento individual y social. En su libro de ensayos El club de los independientes, nuestro autor toma la palabra latina clasis en la acepción de "fragata" o "escuadra" (Pontes Velasco 2005: 8) para referir con exactitud milimétrica a la veintena de escritores, de diversas procedencias, nacionalidades y épocas, que analiza. Los miembros de este 'escuadrón’ incombustible poseen como principal rasgo

\footnotetext{
${ }^{1}$ http://www.lajornadajalisco.com.mx/2007/05/28/index.php?section=cultura\&article=009n2cul.

${ }^{2}$ http://redescolarilce.edu.mx/redescolar/act_permanentes/lengua_comunicacion/palabraescritor/iprincipal/esgsen.htm.
} 
en común sus respectivas individualidades, conformando con su mera presencia una visión definitoria de las obsesiones samperianas.

Los brillantes individuos de este club son poetas, narradores o ensayistas como el archimencionado Jorge Luis Borges, Witold Gombrowicz, Julio Garmendia, Michel de Montaigne, Nathaniel Hawthorne, Guy de Maupassant, Sherwood Anderson, Raymond Carver, Antón Chéjov, Max Aub, Alfonso Reyes, Arthur Rimbaud, Roberto Arlt, André Malraux, Gustav Meyrink, Francisco Tario, Juan Rulfo, Gabriel García Márquez, Jaime Sabines, Marco Antonio Campos, Carlos Pellicer, Rodolfo Walsh o la generación del Crack. Todos ellos adquieren el adjetivo 'clásico' porque sus creaciones se ponen al servicio del plano íntimo de la humanidad, protegiendo con su compañía la soledad del lector que los elige - Samperio - y de los que compartimos esta elección: nosotros.

Junto a un irrenunciable respeto por los modelos, Samperio se distingue por su autonomía a todos los niveles: "Si eres independiente - como ha sido mi caso - sólo puedes confiar en que tu trabajo vale y te sacará adelante. A mí me interesa tener lectores que me lean por verdadero interés o curiosidad, no por otros factores" (Samperio en Salvador García 2002) ${ }^{3}$. Esta independencia conlleva que no se afilie a ningún movimiento literario y selle su pertenencia a este 'grupo ideal', signado por la marcada singularidad de sus socios.

Si el cumplimiento individual está resuelto a través de esta idiosincrasia creativa, no menos clara se establece su realización social. Clásico es sinónimo de ejemplar; es decir, de modelo para artistas noveles o de pautas para la educación de los jóvenes. Cuando Samperio publica libros didácticos para mejorar las destrezas literarias - tales como Después apareció una nave. Recetas para nuevos cuentistas o Cómo se escribe un cuento. 500 tips para nuevos cuentistas del siglo XXI -, en cierto modo se convierte en clásico. Lo mismo sucede cuando varios de sus textos se estudian en institutos mexicanos de secundaria.

Después apareció una nave (2002) se presenta como un manual para cuentistas noveles donde nuestro autor comparte su experiencia como narrador. Con él, se dirige más al futuro escritor que al lector, poniendo dos décadas de bagaje como maestro de talleres literarios al servicio de cualquier persona interesada en armar relatos. Con esta finalidad expone las estrategias retóricas de algunos de sus predecesores, así como sus `argucias' más personales. Nos transmite así el legado de su oficio, aportándonos pistas indirectas para completar el estudio de su proceso creativo.

La publicación de este manual para estudiosos del cuento demuestra que la intuición se refuerza con la conciencia analítica, entroncando con lo que Heinrich Lausberg subraya a propósito de las Geórgicas de Virgilio - "es incumbencia del poeta extraer la función y significado humanos generales entrañados en la ciencia" (1967: 451) - y con la tradición de normatividad clásica que comienza con la Epistola ad Pisones horaciana y que, según las palabras de Antonio García Berrio, confirma que "un artista de aciertos poéticos tan elevados como Horacio puede defender la normalidad técnica del ars, dando convencidas pruebas de su tenacidad pedagógica" (1989: 111).

\footnotetext{
${ }^{3}$ www. literateworld.com/spanish/2002/portada/mar03/w01/topbox3.html.
} 
El didactismo de Después apareció una nave se aprecia en la sutileza de los consejos expuestos, alusivos tanto a la delimitación del impulso inicial - "los cuentos operan como sublimaciones o exorcismos de los problemas del cuentista [...] la gente sin conflicto simplemente no escribe" (2002c: 39) - como a la motivación última de la escritura: "El cuentista muestra una experiencia universal dentro de un acontecimiento singular" (44).

En el prólogo de Cómo se escribe un cuento, Samperio insiste en que cualquier persona, independientemente de su edad, puede escribir buenos textos si conoce las técnicas literarias y se esfuerza por evitar tanto lo insustancial como lo efectista. Su experiencia como director de talleres lo lleva a concluir que los narradores principiantes deben aprender de los clásicos, aunque algunas de sus premisas resulten contradictorias entre sí: "Lo que le funciona a uno le parece nefasto a otro, por ello decidí incluir ambas posturas, las más de las veces en numeración continua, para hacer notar la contradicción y dejar que sea usted, lector, quien elija la que mejor le convenga" (2008: 9).

La noción de que el arte puede transmitirse de maestros a alumnos proviene de Aristóteles, pero Antonio López Eire advierte que ya en la Poética del Estagirita "el propósito de la poesía es el placer, no la enseñanza, pues tampoco lo es la verdad sino que le basta lo verosímil y hasta cabe en ella el paralogismo" (2004: 21). Samperio sabe que la literatura exige la dedicación máxima del escritor; de ahí que apueste por el goce estético siempre que se respete que "cuando se escribe un cuento, nada ni nadie debe ser más importante que la ficción" (2008: 41).

Canonizar la obra de Samperio a través de artículos, tesis o conferencias implica por igual revisitar a los que ya forman parte de la historia literaria como recordar a los que no pudieron o no quisieron entrar en ella. Un requisito que cumple nuestro autor para ingresar en el canon de los clásicos es la extrañeza. Harold Bloom asegura que esta "capacidad de hacerte sentir extraño en tu propia casa" (1994: 13) define lo canónico. Si el crítico estadounidense lleva razón y es cierto que todo texto cuenta con elementos contracanónicos, las peculiaridades formales y temáticas del estilo samperiano han de aceptarse como fundamento de su 'clasicidad'.

González Iglesias precisa que un mecanismo básico para la perduración de un poeta estriba en la revisión de su propia obra a través de las huellas de los maestros: "Es la mejor garantía (en nuestro tiempo y en cualquier otro) para llegar a ser un clásico futuro y presente. Sólo llegará al futuro el que domine el pasado" (2000: 197). Ampliar los límites del canon entraña que una creación individual se proyecte en el conjunto de la tradición literaria, con la condición de que prevalezca la autonomía creadora del autor. El proyecto estético de Samperio no se parece a ningún otro. Para Carlos García Gual, los textos clásicos se caracterizan por "su capacidad de relecturas y reinterpretaciones sin término" (1999: 15). La obra samperiana es clásica porque 'vive’ y permanece en nosotros, en cada una de las interrogantes que formula. Las interpretaciones a las que incita su literatura "admiten infinitos reencuentros" (20-21), lo que la convierte en seria aspirante a ser recordada en el porvenir.

Dado lo relativamente reciente y poco convencional de la propuesta artística de Samperio, hemos creído conveniente trazar una panorámica de sus lecturas y escrituras para comprender mejor sus composiciones. A través a ellas se alza como un `clásico’ que alcanza el reconocimiento por medio de 
su propio camino. La muerte, como indican estas sentencias de Pier Paolo Pasolini, no es sino el paso decisivo a su consagración:

Es necesario morir (absolutamente), porque mientras estamos vivos nos falta sentido; porque en suma mientras hay futuro, es decir, una incógnita, un hombre está inexpresado. La muerte termina como un fulmíneo montaje de nuestra vida, o sea que elige los momentos significativos ya no modificables; por eso es por lo que sólo gracias a la muerte, nuestra vida nos sirve para expresarnos (Pasolini cit. Laurenti, 1976: $85)$.

El idealismo y el materialismo, en último término, se forjan como herramientas para la búsqueda de la felicidad del hombre. El esfuerzo que Samperio desplegó contra los abusos de autoridad no lo condujo a aceptar sin cuestionamiento sus lecturas ni a apostar por una escritura panfletaria; por el contrario, pronto comprendió que el talento se constituye en la mejor arma para enfrentarse a las injusticias de cualquier orden: "Lo más próximo que tenía era la denuncia, pero desde un principio supe que debía atenderse el aspecto artístico y deslindarse del panfleto" (Samperio en Campos 1999: 191).

Extrayendo los mejores recursos de los movimientos literarios de los que se nutrió a lo largo de su vida (como el carácter lúdico de la neovanguardia o la ironía relativizadora de la posmodernidad), liberándose de las desventajas que salieron a su paso (como los prejuicios en cuanto a lo que debe leer un escritor progresista o la angustia por la página en blanco que siente todo creador responsable), y apoyándose en su don para la metáfora como rasgo identificativo, Samperio ha ingresado en el amplio Parnaso de los autores clásicos por la vía de los márgenes, la autoexigencia, el compromiso absoluto con la palabra, la experimentación y la ausencia de concesiones al gran público. No pertenecer a ningún grupo literario de su época se ha correspondido con su adscripción a un 'club de independientes' cuya originalidad y rebeldía los acerca a la inmortalidad.

Con todos los ingredientes aquí expuestos, podemos deducir que Samperio fue feliz leyendo y escribiendo. De algún modo, su sendero hacia la felicidad se completa con su fallecimiento y continuará extendiéndose mientras estudiemos y disfrutemos su apasionante obra.

\section{Bibliografía}

AlAZRAKI, Jaime (1995): "La postmodernidad de Julio Cortázar”, en Carmen RuIz BarRionuevo y César REAL RAmos, eds., La modernidad literaria en España e Hispanoamérica. Salamanca, USAL, pp. 129-137.

BLOOM, Harold (1994): El canon occidental. Trad. Damián Alou. Barcelona, Anagrama, 1997. BORGES, Jorge Luis (1989): Obras completas II (1952-1972). Buenos Aires, Emecé, 1996.

Brasca, Raúl - ChITARroni, Luis, eds. (2004): Textículos bestiales: Cuentos breves de animales reales o imaginarios. Buenos Aires, Instituto Movilizador de Fondos Cooperativos.

CAMPOS, Marco Antonio (1999): “Epílogo-entrevista”, en Guillermo SAMPERIO. La cochinilla y otras ficciones breves. México, UNAM, pp. 177-200.

Círculo Cultural FARONI, ed. (1996): Quince líneas: Relatos hiperbreves. Barcelona, Tusquets. 
DuRÁn, Cecilia (2007): "Presentó Guillermo Samperio Cuentos reunidos, libro que incluye obras de 30 años como cuentista", en http://www.lajornadajalisco.com.mx/2007/05/28/index.php?

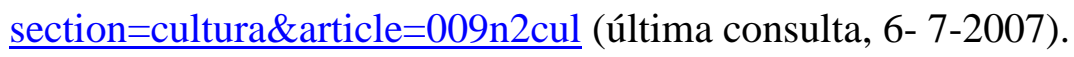

EnZENSBERger, Hans Magnus (1963): “Las aporías de la vanguardia”. Trad. Pablo Simon. Revista Sur, 285, pp. 1-23.

GARCíA, Salvador (2002): “Guillermo Samperio: El deseo de la escritura", en www.literateworld.com/spanish/2002/portada/mar03/w01/topbox3.html (última consulta, 28-22003).

GARCÍA BERrio, Antonio (1989): Teoría de la literatura (La construcción del significado poético). Madrid, Cátedra.

GARCÍA DE LA CONCHA, Víctor (1982): El surrealismo. Madrid, Taurus.

García Gual, Carlos (1999): Sobre el descrédito de la literatura y otros avisos humanistas. Barcelona, Península.

GenetTe, Gérard (1982): Palimpsestos: La literatura en segundo grado. Trad. Celia Fernández Prieto. Madrid, Taurus, 1989.

GonZÁlez IGLESIAS, Juan Antonio (1999): “El triunfo del architexto", en Rafael PÉREz EstradA et alii. El levitador y su vértigo. Madrid, Calambur, pp. 204-224.

(2000): "No me hubiera importado ser Horacio. Autorretratos poéticos de Francisco Fortuny", en M. A. Márquez, A. Ramírez de Verger y R. Zambrano, eds., El retrato literario. Actas del XII Simposio de la Sociedad Española de Literatura general y comparada. Huelva, Universidad de Huelva, pp. 193-201.

(2003): "Borges, Lucano, Séneca y España”, en Carmen RuIZ BARrionuevo, Francisca Noguerol JimÉneZ, M. a Ángeles Pérez LóPEZ, Eva Guerrero GuERrero y Ángela Romero PÉREZ, eds., La literatura iberoamericana en el 2000. Balances, perspectivas y prospectivas. Salamanca, USAL, CD-ROM.

LAURENTI, Roberto (1976): En torno a Pasolini. Madrid, Sedmay.

LAusberg, Heinrich (1967): Manual de retórica literaria. Fundamentos de una ciencia de la literatura. Trad. José Pérez Riesco. Madrid, Gredos, 1991.

LAUTRÉAmont, Conde de (1868): Los cantos de Maldoror. Trad. Manuel Serrat Crespo. Barcelona, La otra orilla, 2007.

LÓPEZ EIRE, Antonio (2004): “La poética de la prepoética. La poética prearistotélica”, en José Antonio SÁnchez MARÍn y M. ${ }^{a}$ Nieves MuÑoz MARTín, eds., Retórica, poética y géneros literarios. Granada, Universidad de Granada, pp. 11-37.

(2005): "La naturaleza retórica del lenguaje", Logo. Revista de Retórica y Teoría de la Comunicación, 8-9, pp. 5-249.

MiLlás, Juan José (2001): Articuentos. Barcelona, Alba.

PÉREZ ESTRADA, Rafael (2001): La palabra destino. Madrid, Hiperión.

PigLIA, Ricardo (2000): Formas breves. Barcelona, Anagrama. 
PONTES Velasco, Rafael (2003): “Guillermo Samperio. El genio precisa todos los ángulos”, Quimera, 227, pp. 55-60.

(2005): "Propios y ajenos. Escritores desde varios espejos", en Guillermo SAMPERIO. El club de los independientes, México, Lectorum, pp. 7- 13.

(2013): La puerta de la cárcel está abierta. La poética de Guillermo Samperio. Salamanca, USAL, CD-ROM.

SAMPERIO, Guillermo (1987): “¿Escritor o bailarina?”, La talacha, 2, pp. 51-52.

(1994): Anteojos para la abstracción. México, Instituto Politécnico Nacional, 1999.

- (1999): Tribulaciones para el siglo XXI. Puebla, UAP.

- (2000): Los franchutes desde México. México, Aldus.

- (2002a): "Brevedades literarias", El Financiero, 8 de febrero, p. 52.

— comp. (2002b): "Prólogo. Damas fantásticas", en Cuentos de damas fantásticas. Madrid, Páginas de Espuma.

- (2002c): Después apareció una nave. Recetas para nuevos cuentistas. México, Alfaguara.

- (2004a): "La ficción breve", en Francisca Noguerol Jiménez, ed., Escritos disconformes. Nuevos modelos de lectura. Salamanca, USAL, pp. 65-69.

- (2004b): La brevedad es una catarina anaranjada. México, Lectorum.

- (2006): Cuentos reunidos. México, Alfaguara.

- (2007): "Guillermo Samperio, cuento, novela y poesía", en http://redescolar.ilce.edu.mx/ redescolar/act_permanentes/lengua_comunicacion/palabraescritor/iprincipal/esgsen.htm (última consulta, 24-6-2007).

— (2008): Cómo se escribe un cuento. 500 tips para nuevos cuentistas del siglo XXI. Córdoba, Berenice.

, comp. (2010): “Rafael Pérez Estrada: El transgresor en el trampolín”, en Rafael Pérez Estrada. Antología de breve ficción. Córdoba, Berenice.

UMBRAL, Francisco (1977): Tratado de perversiones. Barcelona, Argos.

VolPI, Jorge (2008): Mentiras contagiosas. Madrid, Páginas de Espuma. 